\title{
Do encontro previsível à cena revigorada - a entrevista no documentário contemporâneo (parte 1)
}

\author{
Laécio Ricardo de Aquino Rodrigues*
}

Resumo: Primeiro artigo vinculado a um projeto maior, o trabalho problematiza a emergência e o declínio da entrevista na tradição do documentário; em seguida, inspirado em Jean-Louis Comolli, o estudo sugere a reabilitação deste expediente a partir do exemplo de alguns filmes contemporâneos que nos indicam novas políticas do encontro.

Palavras-chave: documentário contemporâneo; entrevista; cinema direto; Comolli.

Resumen: Primer artículo vinculado a un proyecto más amplio, el trabajo problematiza la emergencia y el declinio de la entrevista en la tradición documental; seguidamente, inspirándose en Jean-Louis Comolli, el estudio sugiere la rehabilitación de esta práctica a partir del ejemplo de algunas películas contemporáneas que nos indican nuevas políticas del encuentro.

Palabras clave: documental contemporáneo; entrevista; direct cinema; Comolli.

\begin{abstract}
This is the first paper linked to a larger project of research. Here I focus on the emergence and decline of the interview in documentary tradition. Then, inspired by Jean-Louis Comolli, I suggest the reabilitation of this practice through the analysis of some contemporary movies that indicate other politics of encounter.

Keywords: contemporary documentary; interview; direct cinema; Comolli.
\end{abstract}

Résumé: Premier extrait d'une recherche plus étendue, cet article met en examen l'apparition et le déclin de l'interview dans la tradition du documentaire ; ensuite, motivé par les considérations de Jean-Louis Comolli, le texte suggère la réhabilitation de cette pratique à partir de l'analyse de films contemporains qui dévoilent des nouvelles "politiques de médiation".

Mots-clés: documentaire contemporain; interview; cinéma direct; Comolli.

\footnotetext{
* Universidade Federal de Pernambuco - UFPE, Centro de Artes e Comunicação, Departamento de Comunicação Social, 50670-901, Recife, Brasil. E-mail: laecioricardo@gmail.com

Submissão do artigo: . Notificação de aceitação: .
}

Doc On-line, n. 19, março de 2016, www.doc.ubi.pt, pp. 110-123. 
O presente estudo ${ }^{1}$ integra um projeto de pesquisa recém-aprovado no âmbito do Departamento de Comunicação Social da UFPE e de título homônimo (Do encontro previsível à cena revigorada - a entrevista no documentário contemporâneo). Trata-se, pois, de uma investigação maior que se propõe a reavaliar e mensurar o expediente da entrevista na prática documentária recente, tendo em vista a existência de alguns filmes que nos desafiam a repensar seu emprego convencional, tantas vezes criticado pelo viés burocrático entrevistador e personagem posicionados em zonas de conforto, sem riscos para ambos, integrando uma cena que não solicita qualquer engajamento crítico/político por parte do espectador. Tendo em vista o caráter inicial da pesquisa e a necessidade de contextualização dos impasses que circunscrevem a prática da entrevista no documentário, apresento aqui a primeira parte deste estudo, um ensaio que nos servirá de referência para uma imersão no problema central: a ascensão e o crepúsculo de tal expediente. Nos próximos dois ou três artigos vinculados ao projeto (com periodicidade possivelmente semestral), a investigação será ampliada com a análise de alguns filmes onde, acredito, podemos identificar "respostas" e procedimentos capazes de revitalizar o emprego da entrevista, ou de pelo menos nos indicar vias alternativas.

\section{O documentário moderno e a consagração da entrevista}

O desenvolvimento das tecnologias portáteis de registro síncrono do som e da imagem (tomada direta), em fins dos anos de 1950, juntamente com o florescimento de uma nova ética na relação cineasta/personagem no documentário (ética que limitava o controle do realizador e a pretensão totalizante de muitos filmes), promoveram uma ruptura neste domínio audiovisual: a chamada transição do modelo clássico para o moderno (Barnouw, 1993; Gauthier, 2011). Neste contexto, a estilística clássica, caracterizada pela presença de uma voz over didática e pela afasia dos sujeitos abordados ${ }^{2}$, cede espaço a um fascínio crescente pela fala e pela presença do outro em cena, bem como pela adoção de procedimentos narrativos que valorizam a complexidade do mundo, em vez de reduzi-la a esquemas mecânicos (relações de causa e efeito).

1. Uma versão reduzida deste trabalho foi apresentado no XIX Encontro da Sociedade Brasileira de Estudos de Cinema e Audiovisual, realizado entre 20 e 23 de outubro de 2015, na Universidade Estadual de Campinas - UNICAMP. Essa versão foi encaminhada para inclusão nos anais do encontro, a ser publicada no primeiro semestre de 2016.

2. Emprego aqui o termo "documentário clássico" para me referir, prioritariamente, às produções que adotam uma estilística marcada pelo controle excessivo do realizador (monopólio da voz). Tais obras também se caracterizam pelo enfoque totalizador, que privilegia leituras unívocas. No entanto, reconheço que, sob o rótulo "documentário clássico", figura uma diversidade de propostas e realizadores que não se encaixam nesta descrição. Cito os exemplos de Vertov, de Joris Ivens, de Resnais (produção documental), de Georges Franju e do Free Cinema, dentre outros. 
Esta transição sinaliza a ascensão de uma prática cinematográfica marcada por um menor controle do realizador e por uma maior confiança na desenvoltura dos sujeitos em cena. Em muitos títulos realizados à época, verificamos um retraimento da autoridade do cineasta em benefício de uma afirmação da alteridade filmada - em outros termos, não mais vislumbramos a presença de vozes desincorporadas e nem de corpos emudecidos (corpos que são objeto de uma enunciação unicamente externa). Todavia, apesar da complexidade desse quadro, são comuns as referências que vinculam tal contexto de transição e ruptura unicamente ao desenvolvimento dos equipamentos portáteis de registro síncrono do som e da imagem (ou seja, ao aparato técnico que possibilitou a realização de tomadas diretas ${ }^{3}$ ). Trata-se de um fetichismo tecnológico impreciso, carente de relativização e de esclarecimento ${ }^{4}$ (Rodrigues, 2011). Tal conjuntura, no entanto, também testemunha a consolidação da entrevista como prática de abordagem da alteridade no documentário. ${ }^{5}$

Neste domínio audiovisual, convém ressaltar que a miniaturização/portabilidade dos equipamentos e a redução das equipes permitiram a construção de uma atmosfera de maior intimidade e de menor intimidação entre as partes envolvidas, condições sem dúvida favoráveis à entrevista. De caráter interativo, o emprego deste procedimento desponta prioritariamente na escola do cinemaverdade $(\mathrm{CV})$. Assim, ao assistirmos aos filmes dessa vertente nos deparamos com uma obra realizada por alguém ativamente engajado na representação; suas tomadas nos revelam o corpo-a-corpo dos sujeitos em cena e seus níveis de engajamento, em encontros muitas vezes carregados de emoção. Em certa medida, o que se registra é uma situação/evento que desponta pela mediação e agenciamento do cineasta (inexistente antes do acionamento da câmera), re-

3. A tecnologia que culminou no florescimento dos equipamentos portáteis e síncronos, cabe destacar, não desponta subitamente, sem antecedentes. É importante mencionar aqui as pesquisas com som alavancadas pela escola britânica, em cujo grupo se destacava o brasileiro Alberto Cavalcanti, e as conquistas alimentadas pelo esforço de guerra, por exemplo (o desenvolvimento de películas mais sensíveis e de alguns gravadores portáteis). Todavia, apesar destes avanços, é somente no contexto de transição dos anos de 1950/1960 que o aparato técnico possibilita o pleno êxito da tomada direta.

4. O exemplo protagonizado por Jean Rouch me parece propício para ponderarmos esta complexa relação. Como observa Scheinfeigel (2009), bem antes do advento dos aparelhos portáteis e síncronos, Rouch já estabelecera outro vínculo com os africanos por ele filmados, pautado numa ética que pressupunha a criação como colaboração mútua em vez de espoliação da alteridade - ou conversão desta em artefato exótico a ser exposto nos museus etnográficos do Velho Mundo. Ao recusar os procedimentos da antropologia convencional, Rouch descobre que, apenas refreando suas pretensões eurocêntricas e solicitando a força do imaginário "nativo", poderia contribuir para o florescimento de aspectos contundentes da realidade africana capazes de fecundar seu cinema. Tal gesto nos revela o pioneirismo de sua arte/ciência e nos permite entender a magnitude de uma obra como Eu, um Negro (1958).

5. Embora este contexto possibilite a consagração da entrevista no documentário, cabe mencionar que tal prática encontra antecedentes importantes nesta tradição, como ilustram as experiências de Vertov em Réquiem a Lênin (1934) e o filme Housing Problems (1935), produção britânica dirigida por Edgar Anstey. Um pioneirismo que não pode ser desconsiderado. 
configurando experiências de vida - a dele, a dos personagens e, talvez, a do espectador.

Nessa escola, em vez da discrição pretendida pelos colegas do direto americano, vislumbramos um envolvimento maior do cineasta com o universo abordado no filme. Em síntese, é a presença agenciadora do diretor que estimula derivas narrativas e instiga a fabulação dos personagens, forjando níveis de indiscernibilidade para o espectador e expondo a fragilidade da dicotomia ficção/documentário (Deleuze, 2009). Por conseguinte, em vez de registros orientados por um ideal de "invisibilidade" da equipe, testemunhamos nos filmes desta tradição ${ }^{6}$ unicamente a "verdade de um encontro", com suas hesitações, ambiguidades e a reinvenção de subjetividades diante da câmera. Amparado em texto consagrado de Comolli (2010), poderíamos dizer que tais obras valorizam a inevitável "perversão" ou vocação do direto, ao suscitar migrações subjetivas e ao promover entrelaçamentos entre a ficção e o documentário, diferenciando-se da simples reportagem (para Comolli, a prática televisiva correspondia ao emprego menos notável dos dispositivos de registro síncrono - uma espécie de grau zero do direto).

\section{Apontamentos sobre a entrevista}

Problema central deste estudo, a entrevista não é, evidentemente, uma técnica exclusiva do documentário. Ela está presente no cotidiano das Ciências Sociais, da Medicina, da Psicologia e do Judiciário (testemunhos e depoimentos, lembremos, são procedimentos análogos, motivados por uma voz que solicita do outro uma pronta resposta), além de despontar na prática religiosa - a confissão e a confidência são práticas que estimulam um "falar de si". E, claro, é ferramenta importante para o campo da Comunicação Social - constitui, por exemplo, a principal técnica de apuração de informações no Jornalismo. Se, por um lado, vícios e virtudes da entrevista podem ser observados tanto no documentário quanto nestes domínios, é preciso reiterar que a entrevista no documentário possui especificidades próprias. Tal singularidade vai desde a dilatação do tempo do encontro entre o diretor e o entrevistado, algo distante da pressão do relógio que normalmente rege o ofício jornalístico, até a maior durabilidade do produto final editado, em contraste com o consumo efêmero das notícias diárias (em outros termos, a obra fílmica precisa resistir ao teste do tempo: mesmo visto cinco ou dez anos após a sua finalização, o filme pre-

6. A título de ilustração, cito exemplos de documentários vinculados à esta tradição (cinema-verdade e/ou documentários reflexivos): Crônica de um verão (1960), de Jean Rouch e Edgar Morin; Comícios do amor (1965), de Pasolini; Daguerreótipos (1976), de Agnès Varda A tristeza e a piedade (1969), de Marcel Ophüls; Cabra marcado para morrer (1985) e Santo forte (1999), de Eduardo Coutinho. 
cisa mobilizar algum interesse, expressar atualidade e se comunicar com novos espectadores).

Amparada na oralidade (verbo e gestos entrelaçados), a entrevista, seja no documentário ou na prática jornalística, pode propiciar uma democratização na enunciação (uma redistribuição dos lugares de fala), com limitações evidentes. Assim, se durante sua prática o monopólio da fala se encontra reduzido, podemos dizer que, quase sempre, permanece o monopólio da pergunta (a inviolabilidade do lado que tradicionalmente porta uma dúvida ou questionamento). Uma pesquisadora brasileira, investigando o campo da comunicação, observa que a situação ideal (ou idílica) na entrevista é aquela na qual o diálogo entre as partes é possível (Medina, 2001); um desses raros momentos nos quais o entrevistado e o entrevistador saem 'alterados' do encontro, situação na qual a técnica e a formalidade são ultrapassadas pelo estabelecimento da 'intimidade' entre o EU e o TU (descoberta de si no outro e vice-versa), experiência na qual uma aprendizagem e visão de mundo se afirmam reciprocamente. Mas tal convergência de interesses e de sensibilidades é, de fato, possível?

Como sugere Leonor Arfuch (1995), a entrevista está longe de ser um simples procedimento de coleta de informações; ao contrário, é uma atividade discursiva complexa, que entrelaça redes de subjetividades, que pressupõe protocolos, que cria obrigações, exerce persuasões, controle ou violência. Por outro lado, nos diz ela, a necessidade de, no decorrer da entrevista, manter o interesse do entrevistado no jogo e de mobilizar a atenção do público durante a projeção, é uma dupla preocupação que solicita competências específicas do condutor do processo (preparo prévio, disponibilidade para o outro, capacidade de ouvir e de intervir com precisão...). Afinal, cabe ressaltar que a cena só pode ser composta e mantida se as partes envolvidas estabelecerem um pacto entre si - de um lado, alguém anseia por um relato/informação, por uma palavra revigorada, exclusiva e de provável interesse público; do outro, alguém almeja um canal para verbalizar suas inquietações, sigilos, memórias e ansiedades, ciente de que sua fala será acolhida devidamente.

As observações de Arfuch convergem com algumas considerações de Bill Nichols. Para o autor norte-americano, o mérito da entrevista é permitir que o cineasta se dirija prioritariamente às pessoas na tomada, minimizando, assim, os comentários em voz over voltados ao público e inseridos na edição final uma espécie de embate verbal direto que minimizaria o didatismo da narração explicativa e sobreposta às imagens (2007: 159). Todavia, a exemplo da colega argentina, Nichols também destaca certa dimensão protocolar no emprego desse recurso. Segundo ele, a entrevista seria uma forma distinta de encontro social, uma vez que "difere da conversa corriqueira e do processo mais coer- 
citivo de interrogação"; e, evocando Michel Foucault, ele argumenta que sua prática inclui formas de troca regulamentadas, com distribuição desigual de poder entre as partes envolvidas (2007: 160).

Figura central nesta pesquisa, o francês Jean-Louis Comolli desloca um pouco o debate. Segundo ele, apesar do excesso de entrevistas vislumbrado no cinema e na televisão, este recurso nunca deve ser encarado como banal e, tampouco, sem desafios. Em suas palavras, "convocar alguém para compor uma cena e fazê-lo falar e, eventualmente, escutá-lo [...] nunca foi e nem pode ser um gesto anódino" (2008: 86). Portanto, colocar-se de frente para o outro, numa relação mediada por uma máquina, é um ato de grande responsabilidade e de entrega - trata-se de um duelo, "uma conjugação mais ou menos guiada pelo desejo, mais ou menos marcada pelo medo e pela violência". E se esses dois sujeitos não se comprometem um com o outro, nos diz Comolli, "a máquina capta - cruelmente - a nulidade desse encontro". Em síntese, conclui ele: "não se filma impunemente - menos ainda o corpo do outro, sua palavra, sua presença" (2008: 86).

\section{Dilemas da entrevista na contemporaneidade}

Palco fomentador de importantes conquistas técnicas associadas ao direto, a televisão, com sua lógica de produção subordinada ao espetáculo e à contínua pressão do relógio, gradualmente se transformou no seu algoz - neste domínio, a palavra revigorada nos primeiros documentários modernos foi substituída pelo comentário breve e aos entrevistados não é concedido tempo para manifestar sua visão de mundo (Da-Rin, 2004; Rodrigues, 2011). Todavia, muitos documentários também têm contribuído para este esvaziamento, ao abdicar das tomadas onde a duração era um valor inalienável, o que permitia ao personagem alcançar maior desenvoltura e/ou experimentar novas derivas, e ao converter os sujeitos em talking heads - neste modelo de fácil identificação, os entrevistados são enquadrados acima da cintura e posicionados num eixo diagonal (se dirigem a alguém que permanece ausente do quadro), e seus depoimentos são editados e emparelhados (contrastados entre si) para a corroboração ou retificação das hipóteses articuladas pelo filme. Ou, como resume Bill Nichols, nesta vertente "os cineastas usam a entrevista para juntar relatos diferentes numa única história" (2007: 160); em outros termos, para justapor e entrelaçar pontos de vista originalmente distintos.

Em certa medida, como tudo que se institucionaliza (seu uso recorrente por cineastas menos criativos, mas também seu emprego precário pela grande mídia), a entrevista perdeu força, se converteu em recurso desacreditado, em mero depoimento emitido em "zonas de conforto" - sem riscos para os polos 
envolvidos e sem grandes investimentos da parte do espectador. Na virada dos anos de 1990/2000, não foram poucas as vozes que se insurgiram questionando este emprego viciado do direto e suas limitações.

Defensor inconteste das virtudes do direto e do papel político do documentário (pelo menos de certa prática documentária por ele incensada), Comolli, numa série de ensaios disponibilizados há algum tempo em português, é um dos primeiros a reconhecer tal esvaziamento e a clamar por um revigoramento que distancie o bom cinema dos excessos da grande mídia. "Hoje, quase trinta anos depois, a prática do 'cinema direto' se generalizou de fato e se banalizou", nos diz ele, exemplificando a observação com a popularização das câmeras amadoras; em seguida, complementa em tom crítico: "enquanto a televisão valoriza cada vez mais o uso do 'ao vivo' como prova da verdade, chifre do touro" (2008: 111). Em síntese, as emissoras televisivas restringiriam a potência do direto a um simples expediente de comprovação, de verificação. Em sua avaliação, portanto, a produção da palavra filmada na atualidade seria o lugar de uma guerrilha sem nome: haveria o campo da "palavra destruída", território das corporações midiáticas; e "há aquele da palavra construída após a ruína", missão inalienável do cinema documentário (2008: 120). Mais à frente voltarei às considerações do ensaísta francês, porém, motivado por um ideal de reabilitação da entrevista.

Dentre nós, Teixeira (2003) e Bernardet (2003) talvez tenham sido os críticos mais enfáticos deste esvaziamento ${ }^{7}$. Acompanhemos suas considerações. A valorização da tomada direta no documentário, como destaca Teixeira, levou este domínio a uma curiosa situação: de um estágio inicial de afasia e espoliação da alteridade teríamos saltado, em suas fases moderna e contemporânea, para um quadro de incontinência oral e de banalização da entrevista. Teríamos passado de um estado "de falar pelos que não têm voz", num contexto de monopólio discursivo por parte do cineasta, para o imperativo de "dar a voz ao outro", conduta que elege a interlocução como princípio, num suposto intento de apaziguar a autoridade evidente em qualquer situação de filmagem (2003: 164-165). Tal premissa, malgrado suas intenções, teria ares de falácia. Para o autor, esta guinada não implicou grandes rupturas, tampouco uma democratização da instância enunciativa no documentário, uma vez que o cineasta mantém sua condição de "dono do discurso" e a partilha da palavra, em tais condições, é mediada pelo ambíguo viés da dádiva, que implicaria sempre dívida e má-consciência (2003:165).

7. Penso, aliás, que é sintomático o fato de que ambos tenham redigido seus ensaios num período semelhante. 
Revolvido pelo sentimento de culpa e por ter coisificado a alteridade, o realizador, hoje, se esforçaria para amortizar esse pecado com o exercício de uma escuta (não raro, indiferente) e a restituição da fala ao outro. No entanto, testemunharíamos aqui apenas um gesto de reversibilidade consentida - doada e permitida -, distante de uma reconfiguração enfática da dimensão enunciativa (2003: 165). Em seu texto, Teixeira admite que "dar a voz" é uma prática mais generosa do que silenciar o outro em cena ${ }^{8}$. Contudo, argumenta, tal decisão expõe seus limites quando o diretor, "embora recuse falar em nome do outro ou cortar-lhe a voz, mantém-se em sua identidade inalterada de articulador de um discurso por ele autorizado e acordado" (2003: 165). Em síntese, tal gesto esquemático não converteria a alteridade em sujeito ativo da comunicação.

Bernardet (2003), em ensaio igualmente contundente, incluído na reedição de Cineastas e imagens do povo, estimulou nossos cineastas a repensar o emprego da entrevista. Redigidas de modo mais coloquial, suas colocações se aproximam do mal-estar apontado por Teixeira. "O som direto abriu para o cinema um leque extraordinariamente rico de entrevistas e falas", celebra ele inicialmente, para, em seguida, recuar: "Após esse momento criador [...], a entrevista se generalizou e se tornou o feijão com arroz do documentário cinematográfico televisivo, [...] virou cacoete". A crítica se intensifica:

[Hoje] Não se pensa mais documentário sem entrevista, e o mais das vezes dirigir uma pergunta ao entrevistado é como ligar o piloto automático. Faz-se a pergunta, o entrevistado vai falando e está tudo bem; quando esmorecer, nova pergunta (2003: 284 a 286).

Para Bernardet, o relativo aumento das produções neste domínio não teria sido acompanhado de renovações estilísticas e narrativas. "Se, nos primórdios do cinema direto, a entrevista era um tentativa de encontrar o outro", pondera, [hoje] "se tornou automatismo" (2003: 286). De modo sintético, podemos resumir os argumentos centrais que impulsionam o ensaio: a contínua aclamação de Eduardo Coutinho (de cuja obra Bernardet é entusiasta) pela crítica/academia teria promovido sua influência inconteste no campo do documentário, herança que, por sua vez, incentivara alguns realizadores a emular sua prática sem êxito (ele seria uma espécie de sombra nem sempre positiva). Paralelamente, e de modo não desconectado da primeira constatação, Bernardet aponta a falta de criatividade dos documentaristas para empregar a entre-

8. Embora replicada com frequência na historiografia crítica do documentário (sobretudo na tradição brasileira), é preciso ressaltar certa inadequação da expressão "dar a voz", ainda que a prática vislumbrada pelo cineasta em seu desejo de abordagem da alteridade, seja o de estabelecer uma interlocução marcada por um menor controle e uma maior autonomia do "outro". Penso que o texto de Teixeira é um dos mais enfáticos na desconstrução deste ideal idílico (ideal que termina por mascarar uma autoridade inevitável e a negociação que preside qualquer tomada); todavia, talvez seja hora de pensarmos também na revisão terminológica da expressão e em seu possível desuso. 
vista de modo inovador - não raro, alguns até converteriam sua prática num exercício narcísico onde o vetor da conversa se dirige à personalidade do cineasta, em vez de priorizar o outro à sua frente.

Por fim, Bernardet insiste que a primazia conferida a este jorro verbal empobrecido levara os documentaristas a se descuidar da banda visual do filme, bem como com os sons/ruídos que despontam fora do contexto de interação entre o diretor e os sujeitos por ele abordados, além de pouco valorizar a interação dos personagens entre si (aspecto priorizado por Jean Rouch, por exemplo). Penso que esta crítica enfática, tendo em vista a ressonância de Bernardet no segmento audiovisual brasileiro, trouxe consequências imediatas como o gradual abandono da entrevista, em sua modalidade convencional, por gerações recentes de documentaristas e o estímulo à adoção de "dispositivos" como fundamento do processo criativo, no intuito de, quem sabe, reposicionar a entrevista em outros parâmetros ${ }^{9}$ (desdobrarei esta hipótese em outro texto derivado desta pesquisa).

Todo este longo percurso para chegarmos a uma conclusão desconfortável: como tudo que esbanja originalidade em seu nascedouro ${ }^{10}$, a tomada direta em sua prática mais sedutora - a entrevista - gradualmente se esvaziou, perdeu fôlego, em virtude de suas apropriações limitadas. Todavia, não obstante tal diagnóstico, é preciso lembrar que a entrevista ainda permanece como um expediente recorrente no documentário, como atesta sua prática em muitos títulos recentes, alguns com resultados surpreendentes e encorajadores. Assim, em sintonia com Comolli (2008), acreditamos que ela não pode ser descartada em virtude do emprego precário, dos pecados no varejo. Caberia, antes, repensar a entrevista, reavaliá-la e reativá-la enquanto instrumento capaz de reabilitar a potência dos encontros na tomada direta. Deste modo, amparado no ensaísta francês e na contramão dos trabalhos que ratificam o seu esvaziamento, este estudo propõe reabilitar as potências da entrevista na contemporaneidade, destacando o seu uso criativo em alguns títulos produzidos pós-1990 (obras que converteram o evento previsível do encontro em cenas

9. Conferir: RODRIGUES, Laécio. "Notas sobre o dispositivo no documentário contemporâneo" in Galáxia, Revista do Programa de Pós-Graduação em Comunicação e Semiótica da PUC-SP, São Paulo, n. 30, pp. 138-148, dez. 2015. ISSN: 1982-2553. Disponível em: http://revistas.pucsp.br/index.php/galaxia/article/view/20160.

10. Nunca é demais relembrar a fulgurância da entrevista no período de afirmação do cinema direto. Neste contexto, é conhecido o quanto o seu emprego contribuiu para revigorar o documentário (pensemos na obra de Jean Rouch; Shirley Clarke, Marcel Ophüls, Pierre Perrault e Claude Lanzmann, dentre outros), seja via estímulo da potência fabuladora dos personagens (Deleuze, 2009) ou unicamente como exercício interativo/investigativo. No caso brasileiro, embora tenhamos muitos exemplos, certamente Eduardo Coutinho foi o cineasta que melhor nos apresentou as virtudes da entrevista para revolver as subjetividades dos sujeitos por ele interpelados em cena, estimulando derivas narrativas inesquecíveis. 
revigoradas). ${ }^{11}$ Neste empreendimento, desejamos ressaltar que, em vez de homogênea, a prática da entrevista é complexa e heterogênea. Em outros termos, são muitas as possibilidades de condução e realização de uma entrevista. E cada uma delas solicita diferentes formas de engajamento na tomada entre cineastas e sujeitos filmados.

Ainda em diálogo com Comolli, ressaltamos que, num mundo ruidoso de falas e num cinema marcado pelo mutismo do outro, é tarefa do documentário (em tomada direta) contribuir para o ressurgimento da potência da palavra corporificada - com sua multiplicidade de sentidos, com seus ritmos e encadeamentos próprios. Assim, ante o discurso daqueles que censuram o uso frequente da palavra no documentário e consideram que, em virtude dos excessos no varejo, sua manifestação deve ser refreada, Comolli avança na direção contrária - é preciso que o documentarista, mais do que nunca, se invista da palavra e do corpo das pessoas filmadas. E que também ele se implique na tomada com seu corpo e voz. ${ }^{12}$

Afinal, se "filmar um outro é confrontar a minha mise-en-scène com aquela desse outro", promovendo desestabilizações e aprendizado mútuo, também cabe lembrar que é tarefa do cinema opor-se à indiferença e à lógica midiática, exaltar os desejos, aproximar os povos e engajar os espectadores na tomada. "É preciso, então, antes de tudo, que a indiferença relativa de um espectador", tradicionalmente alijado da cena nos registros televisivos, "seja contrariada pelo trabalho do filme até se transformar em implicação" (2008: 105). Uma questão de inscrição (quais as regras que presidem a realização da tomada) e de escritura (como manusear o material bruto) parecem estar no epicentro do debate, opondo o cinema político ambicionado pelo autor às obras que recaem nas teias do espetáculo:

Tudo é escritura, mas nem todas as escrituras se equivalem e apenas algumas podem pretender, além de sua eficácia, uma honestidade ou autenticidade. Como julgá-las? Rejeitando os procedimentos que desprezam o espectador. Um espectador desprezado representa desprezo para todos os outros. E vemos

11. Numa primeira triagem, delimitamos alguns títulos para as etapas futuras desta pesquisa Obras internacionais: Close up (1990), Salve o cinema (1995), Os catadores e eu (2000), Sob a névoa da guerra (2003), Vinguem tudo, mas deixem um de meus olhos (2005), Z-32 (2008), S-21 - A máquina de morte do Khmer Vermelho (2003), O peso do silêncio (2014). Filmes brasileiros: O fim e o princípio (2005), Jogo de Cena (2007), A margem do corpo (2006), A falta que me faz (2009), Doméstica (2012), Os dias com ele (2013) e Mataram meu irmão (2013).

12. Comolli, lembremos, defende uma prática cinematográfica que implica investimento político e doses de violência (sedução, entrega e desconfiança seriam gestos inerentes a esta arte), mas também acolhimento e abertura para o mundo. Para o francềs, filmar em tomada direta implica abrir a cena à vida de modo que o real possa fecundar a representação, promovendo fissuras e implodindo o que estava programado - gesto político que, em sua radicalidade, também comporta a possibilidade de não haver filme algum (Comolli, 2008). 
este desprezo, dia após dia, agir nos procedimentos da televisão, moldada pela publicidade (Comolli, 2008: 120).

Contra a indiferença e o desprezo (ante a alteridade e o espectador, respectivamente), portanto, concordamos com Comolli quando o ensaísta sugere que "filmar é trazer cinema ao mundo, transformá-lo em cinema" (2008: 120). Ou quando ressalta que, em seu empreendimento político, é tarefa do cineasta perceber que algo da experiência resiste: não obstante a onipresença dos roteiros, do cálculo e do controle, alguém anseia por falar e algo espera por ser apreendido livre das interdições e da violência perpetradas pela grande mídia. É difícil não perceber nesta observação uma proximidade com o belo ensaio de Didi-Huberman sobre as sobrevivências dos vagalumes - precisa metáfora para as existências que resistem em nosso tempo, não obstante o terror e a escuridão provocados pelos regimes autoritários, ou os holofotes excessivos do espetáculo que ameaçam tudo ofuscar (2011). Assim, só nos resta concordar com a promissora hipótese aventada por Comolli:

Eu me pergunto se a ambição (pouco declarada) do documentário não seria, filmando esse comum, restabelecer para ele e para nós a ideia, mais que comprometida pela espetacularização crescente das sociedades humanas, de certa dignidade do ser (2008: 122).

\section{Apontamentos finais}

Por conseguinte, se o campo da palavra destruída (composto pela grande mídia em suas práticas orientadas por laços econômicos e ideológicos) persiste em sua amplitude e contundência, é preciso não desistir do campo da palavra construída após a ruína personificado por certa produção documentária que, embora minoritária, trafega na contramão do espetáculo e das fórmulas repisadas. Assim, em sintonia com Comolli, acredito que a prática da entrevista não pode ser desacreditada ou menosprezada em virtude dos excessos no varejo, tendo em vista que estas sobrevivências fílmicas (vestígios de resistência) nos sugerem possibilidades de reinvenção desse recurso.

Portanto, nos próximos ensaios vinculados a esta pesquisa, desejo investir na análise de algumas obras estética e politicamente potentes, obras que trafegam por vias que desafiam a monotonia do espetáculo, confrontando a autoridade do realizador e estabelecendo uma chave emancipada de leitura e engajamento (Rancière, 2010). Tais títulos, insisto, contribuem para revitalizar o cinema direto e reequacionar a relação cineasta, alteridade, espectador, além de nos indicar uma outra política dos encontros e novas pedagogias para a prá- 
tica da entrevista. ${ }^{13}$ Seja por meio de procedimentos reflexivos, ensaísticos e críticos que nos estimulam a dela desconfiar (da entrevista), seja por meio de práticas inscritivas que, ao se abrir para certos riscos, tensionam a cena com o signo do imprevisível.

\section{Referências bibliográficas}

Arfuch, L. (1995). La entrevista, una invención dialógica. Barcelona: Paidós.

Barnouw, E. (1993). Documentary: a history of the non-fiction film. Nova York: Oxford University Press.

Bernardet, J.C. (2003). Cineastas e imagens do povo. São Paulo: Companhia das Letras.

Comolli, J.-L. (2008). Ver e poder - A inocência perdida: cinema, televisão, fiç̧ão, documentário. Belo Horizonte: Editora UFMG.

Comolli, J.-L. (2010). O Desvio pelo Direto. Catálogo do 14 ${ }^{o}$. Festival do Filme Documentário e Etnográfico - Fórum de Antropologia, Cinema e Vídeo (Forumdoc.BH): 294-317. Disponível em http://www.forumdoc.or g.br/2010/catalogo2010.pdf. Estes ensaios foram originalmente publicados em Cahiers du Cinéma, n. 209, fevereiro, e n. 211, abril, de 1969, com o título "Le détour par le direct".

Da-Rin, S. (2004). Espelho partido - Tradição e transformação do documentário. Rio de Janeiro: Azougue Editorial.

Didi-Huberman, G. (2012). Imagens apesar de tudo. Lisboa: KKYM.

Didi-Huberman, G. (2011). Sobrevivência dos vaga-lumes. Belo Horizonte: Editora UFMG.

Gauthier, G. (2011). O documentário: Um outro cinema. Campinas: Papirus.

Marcorelles, L. (Org.) (1973). Living cinema. London: Cox \& Wyman.

Marsolais, G. (1974). L'aventure du cinéma direct. Paris: Seghers.

Medina, C. (2001). Entrevista - o diálogo possível. $4^{a}$ edição, São Paulo: Editora Ática.

13. Como já ressaltei, entendo que só podemos falar do procedimento da entrevista no plural: ou seja, não existe uma única forma de se entrevistar, mas diferentes práticas de agenciamento na tomada. Portanto, se a grande mídia com frequência restringe a fertilidade deste método (juntamente com os documentários que, interessados numa suposta interlocução apenas repõem a autoridade da figura do diretor), adotaremos como objetivo, em estudos futuros, o delineamento de uma tipologia dos modos possíveis de organização e realização de uma entrevista - das diferentes relações que podem ser estabelecidas entre aquele que filma e aqueles que aceitam adentrar o quadro e partilhar uma duração, concedendo à equipe (e ao espectador) fatias verbais de sua experiência. 
Rancière, J. (2010). O espectador emancipado. Lisboa: Orfeu Negro.

Rodrigues, L.R.A. (2011). Potência e arrefecimento do direto no documentário. Doc On-Line - Revista digital de cinema documentário, (11): 134158, dez. Disponível em http://www.doc.ubi.pt/11/dossier_laecio_rodri gues.pdf.

Rodrigues, L.R.A. (2015). Notas sobre o dispositivo no documentário contemporâneo. Galáxia, Revista do Programa de Pós-Graduação em Comunicação e Semiótica da PUC-SP, (30): 138-148, dez. São Paulo. ISSN: 1982-2553. Disponível em: http://revistas.pucsp.br/index.php/galaxia/ar ticle/view/20160.

Sarlo, B. (2007). Tempo passado: cultura da memória e guinada subjetiva. São Paulo: Companhia das Letras; Belo Horizonte: UFMG.

Scheinfeigel, M. (2009). Estilhaços de Vozes (Robinson não diz seu verdadeiro nome). Revista Devires, 6(2): 12-27, Julho/Dezembro. Disponível em http://www.fafich.ufmg.br/ devires/v6n2/download/02-Maxime.pdf

Teixeira, F.E. (2003). Enunciação do documentário: O problema de "dar a voz ao outro. In M. Fabris et al. (Orgs.), Estudos Socine de Cinema, Ano III (pp. 164-170). Porto Alegre: Editora Sulina.

\section{Filmografia}

A falta que me faz (2009), de Marília Rocha

A margem do corpo (2006), de Débora Diniz

A tristeza e a piedade (1969), de Marcel Ophüls

Cabra Marcado para Morrer (1985), de Eduardo Coutinho

Close up (1990), de Abbas Kiarostami

Comícios do Amor (1965), de Pasolini

Crônica de um Verão (1960), de Rouch e Edgar Morin

Daguerreótipos (1976), de Agnès Varda

Doméstica (2012), de Gabriel Mascaro

Eu, um Negro (1958), de Jean Rouch

Housing Problems (1935), de Edgar Anstey

Jogo de Cena (2007), de Eduardo Coutinho

Os catadores e eu (2000), de Agnès Varda

Mataram meu irmão (2013), de Cristiano Burlan 
O fim e o princípio (2005), de Eduardo Coutinho

O peso do silêncio (2014), de Joshua Oppenheimer

Os dias com ele (2013), de Maria Clara Escobar

Réquiem a Lênin (1934), de Vertov

S-21 - A máquina de morte do Khmer Vermelho (2003), de Rithy Panh

Salve o cinema (1995), de Mohsen Markhmalbaf

Santo Forte (1999), de Eduardo Coutinho

Sob a névoa da guerra (2003), de Errol Moris

Vinguem tudo, mas deixem um de meus olhos (2005), de Avi Mograbi

Z-32 (2008), de Avi Mograbi 